and education in Great Britain, in which he has played an outstanding part and thereby made a lasting contribution to the well-being of agriculture. T. J. Boswok'rH

\section{Commander J. Hennessy, M.B.E.}

The sudden death, in his sixty-ninth year, on May 22 of Commander J. Hennessy, deputy marine superintendent of the Meteorological Office, is announced with regret. Commander Hennessy had been deputy marine superintendent of the Meteorological Office since 1919; but during the Second World War he was in sole charge of the Marine Branch of that Office, in the absence of the Marine Superintendent on active service.

Hennessy played an important part in the reorganization of the fleet of voluntary observing ships after the First World War. This was afterwards developed, in 1930, into the 'Selected Ship' system, whereby weather reports are received by radio from merchant ships all over the world at selected meteorological centres. This forms a modern development of the scheme introduced by Maury in $\mathbf{1 8 5 5}$ for the collection of weather information from merchant ships.

Commander Hennessy played a considerable part in organizing the statistical treatment of marine meteorological data. In 1921 the Hollerith punched card system was adopted in the Marine Branch in order to facilitate analysis of the enormous amount, of data in ships' meteorological logs which had accumulated and which had previously been laboriously extracted by hand. There is little doubt that without the aid of such a system the compilation of world-wide climatological statistics for all oceans and the resultant preparation of comprehensive marine meteorological atlases which was carried out during the War under Hennessy's direction--in consultation with the Admiralty-would have been an almost impossible task. Since the data used for these atlases covered as long a period as 1855-1939, account had to be taken of the frequent, but unavoidable, changes in international meteorological procedure and codes. The resulting atlases are probably the most accurate and comprehensive of their type in existence.

Among the other work with which Commander Hennessy was closely associated, the preparation of atlases showing the surface currents of the oceans, compiled also from ships' observations, and of atlases giving the distribution of sea ice may be mentioned. He also took a large share of the responsibility for fitting up the British and Norwegian ocean weather ships and the subsequent administration of the former.

Hennessy was a member of the Commission for Maritime Meteorology of the World Meteorological Organization. He was made M.B.E. in the New Year Honours for 1953.

Commander Hennessy not only possessed a squarerigged master's certificate but also had sailed as first mate in a sailing ship-the barque Miniven. He later served in steamships and was in command of the Northwest Transport Company's Uranium. During the First World War, as a lieutenant R.N.R., he served aboard the armed merchant cruiser Carmania and was present during her famous battle with the German Cap Trafalgar. He also took part in the Dardanelles landings, aboard H.M.S. Hussar, and was later in command of that ship.
Commander Hennessy will be much missed by his many friends in the meteorological world and in shipping circles. $\mathrm{He}$ had a very likeable personality ; his outstanding characteristics were loyalty and devotion to duty and a fine sense of humour. $\mathrm{He}$ is survived by a widow and two sons.

\section{FrANKCOM}

\section{Prof. F. London}

Fritz London, who died on March 30 at the age of fifty-four years, belonged to those theoretical physicists who in the years between 1920 and 1930 began their first investigations under the guidance of Sommerfeld, and soon were able to make contributions of very great importance. In these years only a very few posts were available for theoretical physicists, and like several others, he aimed at first at a different profession. He took his Ph.D. in Munich in 1921 with a paper on philosophy and started to prepare himself for a teaching career. However, the attraction of theoretical physics overwhelmed his sober plans. His first paper appeared in 1925 (jointly with $H$. Hönl) and deals with the rules for the intensities of band spectra. Investigations of this type preceded the development of modern quantum mechanics which essentially was completed in 1927. In this year London met W. Heitler in Zurich, where they wrote their classic paper on the homopolar chemical bond. It led to the interpretation of chemical valence in terms of electronic spin and has remained the basic paper on which a vast amount of work by both physicists and chemists has been built. Further developments led to the theory of activation energy in chemical reactions; another important step was the recognition that the tetravalency of carbon is not due to its ground state but to an excited state. Investigation to a higher degree of accuracy of the forces between atoms led in 1930 (in a joint paper with Fisenschitz) to a quantitative understanding of the long-range forces known as van der Waals attraction.

London had spent the ycars 1928-33 in Berlin where he was Privatdozent at the University. In 1933 he went to the Clarendon Laboratory in Oxford and became interested in the old problem of superconductivity. His brother Heinz had just advanced interesting new ideas on this subject, and jointly they found a phenomenological description of the electromagnetic properties of superconductors known now as the London equations. It is on this subject that London has published several monographs which greatly stimulated both theoretical and experimental research.

In 1936 London went to the University of Paris as Maître (later as Directeur) de Recherche, and in 1939 at the beginning of the war to the United States as professor of theoretical (later of physical) chemistry at Duke University. In these years he again extended the subject of his previous interest. Superconductivity had attracted his attention to the high diamagnetism of certain molecules, on one side, and to the superfluidity of liquid helium on the other. In both subjects he found novel points of view linking up with his previous investigations on the structure of matter.

In 1948 he learned that he was suffering of a dangerous heart disease. Thanks to the devotion of his wife, this did not lead to a flagging of his activity and he continued with all his previous fervour in his investigations. The course of London's life was inevitably influenced by the political upheavals of the last few decades; but he moved through all these changes himself unchanged.
H. FröhLICH 